\title{
Behavioral Optimal Taxation: The Case of
}

\author{
Aspirations
}

Matthias Weber*

February 18, 2019

\begin{abstract}
I provide a simple two-period model comparing lump-sum taxes with proportional labor taxes. The difference to the classical optimal taxation literature is that I introduce a behavioral twist according to which people's aspirations change from one period to another as suggested by empirical evidence. It turns out that the policy implication from this model can differ significantly from the one assuming full rationality. In the behavioral model, a lump-sum tax is much less attractive. This paper does not aim at providing a full-fledged quantitative model, it should rather be seen as a cautionary tale about the robustness of classical optimal taxation results when deviating from full rationality.
\end{abstract}

JEL codes: H21; D90; D60; H20

Keywords: Behavioral public finance; behavioral optimal taxation; aspirations; Easterlin Paradox

*School of Finance, University of St. Gallen \& Faculty of Economics and Business Administration, Vilnius University. Email: matthias.weber@unisg.ch. 


\section{Introduction}

Optimal taxation theory has, as almost all of economics, almost exclusively assumed fully rational economic agents over many decades. However, evidence that human behavior systematically deviates from rational choice is abundant. There are now a considerable number of papers documenting non-rational behavior relevant for taxation (e.g., Kerschbamer and Kirchsteiger, 2000; Sausgruber and Tyran, 2005; Chetty et al., 2009; Sausgruber and Tyran, 2011; Fochmann et al., 2012; Blumkin et al., 2012; Carpenter et al., 2016; Weber and Schram, 2017). The abundance of evidence of nonrational behavior has lead scholars to call for or engage in the development of behavioral models for welfare evaluations (Bernheim and Rangel, 2005; McCaffery and Baron, 2006; Kőszegi and Rabin, 2008; Riedl, 2010; Mullainathan et al., 2011; Chetty, 2015). However, such models are still extremely rare in the field of optimal taxation (some notable exceptions are O’Donoghue and Rabin, 2006; Chetty et al., 2009; Farhi and Gabaix, 2015; Gerritsen, 2016). The question whether the results obtained in a rich literature of optimal taxation theory carry over to a world populated by actual humans rather than rational agents is clearly important. How robust are the classical results to assuming non-rational behavior?

In this short paper, I formulate a very simple two-period model introducing changing aspirations. The idea behind the model is based on the following observation and empirical evidence. While happiness (a term that I use interchangeably with utility) and wealth have many times been shown to be positively correlated (e.g., Hagerty and Veenhoven, 2003), there is also evidence that people's utility received from wealth or income changes. How this utility changes depends on how much money one had (and spent) in the past. A poor person who receives a certain amount of money will afterward be much happier than a rich person who loses money (assuming that their total wealth after these changes is equal). Easterlin (2001) explains this with rising aspirations. He reckons that the aspirations a person has rise with his or her income, such that over the span of a life happiness stays on average similar, although income rises substantially. These changes in aspiration are not foreseen by people, meaning that 
they think their happiness will be higher in the future (anticipating higher earnings) than it will actually be. When making decisions people thus do not take into account that their aspirations will change in the future, leading them to suboptimal decisions.

I introduce a model in which a representative agent maximizes what he believes to be his life-time utility (I will use the masculine form for the representative agent throughout - who considers this inappropriate may possibly be appeased by the fact that this is a behavioral model, that is, the agent is "stupid"). The model assumes that the government needs to raise a certain amount of tax revenue in each period (without specifying the reason for this; one may think of ensuring that the rule of law prevails). It can raise the revenues either with a lump-sum tax or with a proportional tax on labor income. With this model, it can be analyzed how the representative agent's experienced life-time utility (in short real utility), which is the social welfare measure used in this paper, ${ }^{1}$ can be different under the two tax regimes.

The evaluation of the two tax regimes can be remarkably different from the normative evaluation in a fully rational model, where a lump-sum tax is generally preferable. The reason for the result in a rational world is that a proportional labor tax leads to a disincentive to work, reducing labor supply. However, as less labor is supplied in the economy, the government needs to set a relatively high tax rate to obtain a given level of revenue. Overall, social welfare is then lower than under a lump-sum tax where no disincentives to work are present. In the behavioral model, the introduction of aspirations adds a dimension. When deciding how much to work in the first period, the agent ignores that higher consumption in the first period will translate into higher aspirations in the second period (higher aspirations in the second period reduce the agent's utility in that same period). Therefore, without any taxes in place, the agent supplies too much labor. Ex post, in or after the second period, the agent regrets his excessive labor supply in the first period (this model thus corresponds to the anecdotal evidence that people on their deathbed often regret having worked too much, while hardly anyone

\footnotetext{
${ }^{1}$ What kind of utility should be used for welfare considerations is not trivial. I consider experienced utility as the right concept for welfare evaluation, in line with Kahneman et al. (1997), Easterlin (2001), and Kahneman (2003).
} 
regrets not having spent enough time working). As a proportional labor tax provides a disincentive to work it can be welfare enhancing by reducing excessive labor supply.

A few disclaimers are in place to put the model into perspective. While I believe that lump-sum taxes are a bad idea, the mechanism in this model makes up for at best a very minor part of this. I believe that the mechanism introduced in this paper exists, but I think that other factors are much more relevant. However, all other things that can lead to a superiority of a proportional tax over a lump-sum tax are absent in the introduced model by assumption, just as in many economic models. This includes distributional concerns (there is no heterogeneity in the model) or the sensitivity of output and social welfare to decisions of poorer individuals (for example, because decisions about whether to engage in criminal activities or about hazardous lifestyles, including drug consumption, and their implications on government safety nets and health insurance systems, are absent). That lump-sum taxes are, in my opinion, a bad idea does not mean that I think proportional labor taxes are necessarily a good way to raise tax revenue. However, other ways of raising revenue are similarly absent in this model (as in many others), including progressive labor taxes, capital income taxes, consumption taxes, excise taxes on unhealthy or environmentally harmful products, wealth and property taxes, inheritance and remittance taxes, financial transaction taxes, etc. This paper is thus not supposed to be read as an absolute statement about the benefits of a proportional labor tax. Obviously, the model neither attempts to be a quantitative model to be used for the estimation of optimal tax levels or any parameters. Instead, the paper should be seen as providing a neat and simple model analyzing the effect of one single behavioral mechanism (changing aspirations) and as an illustration of how a classical result of optimal taxation theory can break down when a behavioral mechanism is taken into account.

The paper is structured as follows. In Section 2 the model is developed. Section 3 contains the results and some discussions. Section 4 concludes. 


\section{Model}

I first describe the general model, giving the specifics of the agent's decision utility, his experienced utility, and his decision problem(s) in the absence of any taxes (Sections 2.1 and 2.2). Then I introduce a lump-sum tax in Section 2.3. In Section 2.4, I consider a proportional labor tax instead.

\subsection{The Agent's Decision Problem}

A representative agent tries to maximize his life-time utility in a two-period model, where he derives utility from consumption and leisure. He can choose $c_{1}, c_{2}, h_{1}$ and $h_{2}$ denoting consumption in periods 1 and 2 and work time in periods 1 and 2. The maximal work time is normalized to one, such that $h_{1}, h_{2} \in[0,1]$. The wage rate in period $1, w_{1}$ is exogenous, the wage rate in period 2 is $w_{2}=w_{1}+\phi h_{1}$, with $\phi \geq 0$ representing an increase in the wage rate depending on the amount of time worked in the first period (this can be viewed as more work experience leading to a higher salary). There is no possibility to save money. When taking his decisions for the first period, the agent assumes his (discounted) life-time utility to be

$$
u^{*}\left(c_{1}, h_{1}, c_{2}, h_{2}\right)=\log c_{1}+b \log \left(1-h_{1}\right)+\beta\left(\log c_{2}+b \log \left(1-h_{2}\right)\right),
$$

with $\beta \in(0,1]$ and $b>0$. In the absence of taxes, the agent thus solves the following constrained optimization problem (where the two constraints are obviously binding):

$$
\begin{gathered}
\max _{c_{1}, h_{1}, c_{2}, h_{2}} u^{*}\left(c_{1}, h_{1}, c_{2}, h_{2}\right), \\
\text { s.t. } c_{1} \leq h_{1} w_{1}, \\
c_{2} \leq h_{2}\left(w_{1}+\phi h_{1}\right) .
\end{gathered}
$$

So far, the model is just a regular economic model with a rational agent. The model does not yet account for a change in aspirations depending on consumption. For the 
agent's decision utility before/in the first period, aspirations also should not be included, because the agent does not know that his aspirations will change. Aspirations enter the model in the following way. While the agent maximizes $u^{*}$ as given in Equation (1), his experienced (or real) life-time utility is

$$
u\left(c_{1}, h_{1}, c_{2}, h_{2}\right)=\log c_{1}+b \log \left(1-h_{1}\right)+\beta\left(\log c_{2}-\delta \log c_{1}+b \log \left(1-h_{2}\right)\right),
$$

with $\delta>0$. The agent's utility in the second period does not only depend on second period values, but also on the consumption in the first period. His aspirations in the second period increase with consumption in the first period, so that utility in the second period decreases with consumption in the first period (for fixed $c_{2}$ and $h_{2}$ ). The agent is thus not fully rational - he maximizes what he considers to be his life time utility, but he does not maximize his real life-time utility as he does not know that his future aspirations change in dependence of current consumption.

\subsection{The Agent's Decisions after the First Period}

The model, as it is given now, looks like the agent is making a plan how much to consume and to work in both periods before period 1 and then sticks to this plan throughout. But what happens after the first period, when the agent can revise his choices for the second period (when he becomes aware of the correct experienced utility function in period 2)? The answer is that the solution of the model remains the same.

Introducing aspirations into the model in the way I have done changes the model as compared to a standard model twofold. The first difference is that experienced utility in the second period does not only depend on consumption and leisure, but also on past consumption. The second difference is that the agent does not know this dependence of current utility on past consumption. This way of modeling is consistent with the evidence that when people have to indicate how happy they were in the past or how happy they think they will be in the future, they make these evaluations using their current level of aspirations (Easterlin, 2001). In this model, this means that the agent 
in period 1 takes suboptimal decisions concerning period 1 consumption and leisure, because he does so with an incorrect period-2 utility function in mind. After period 1, he perceives his current utility correctly and could thus choose a different combination of consumption and leisure for period 2 than originally planned. However, this does not happen. The agent would in general choose different values for both periods if he knew his experienced period-2 utility before period 1. But if he maximizes $u^{*}$ as given in Equation (1) in the first period, the second period values that maximize $u^{*}$ for fixed $c_{1}$ and $h_{1}$ are the same as the second period values that maximize $u$ as given in Equation (3) for the same fixed values of $c_{1}$ and $h_{1}$.

\subsection{The Model with a Lump-Sum Tax}

When lump-sum taxes $\tau_{1}$ (in period 1) and $\tau_{2}$ (in period 2) are introduced, the agent solves the optimization problem

$$
\begin{gathered}
\max _{c_{1}, h_{1}, c_{2}, h_{2}} u^{*}\left(c_{1}, h_{1}, c_{2}, h_{2}\right), \\
\text { s.t. } c_{1} \leq h_{1} w_{1}-\tau_{1}, \\
c_{2} \leq h_{2}\left(w_{1}+\phi h_{1}\right)-\tau_{2},
\end{gathered}
$$

where $\tau_{1} \geq 0$ and $\tau_{2} \geq 0$ are known in advance.

The first order conditions (that lead in the range of admissible values also to the global maximum) are as follows:

$$
\begin{aligned}
\frac{-b}{1-h_{1}}+\frac{w_{1}}{c_{1}}+\frac{\beta h_{2} \phi}{c_{2}} & =0, \\
\frac{-b}{1-h_{2}}+\frac{w_{1}+\phi h_{1}}{c_{2}} & =0, \\
h_{1} w_{1}-\tau_{1}-c_{1} & =0, \\
h_{2}\left(w_{1}+\phi h_{1}\right)-\tau_{2}-c_{2} & =0 .
\end{aligned}
$$


The multipliers have already been substituted, thus the equations are in the four unknowns $c_{1}, h_{1}, c_{2}$ and $h_{2}$. Numerical solutions for this system of equations can easily be obtained.

\subsection{The Model with a Proportional Labor Tax}

When the government relies instead on a proportional labor tax with tax rates $\kappa_{1}$ (in period 1) and $\kappa_{2}$ (in period 2), the agent solves the optimization problem

$$
\begin{gathered}
\max _{c_{1}, h_{1}, c_{2}, h_{2}} u^{*}\left(c_{1}, h_{1}, c_{2}, h_{2}\right), \\
\text { s.t. } c_{1} \leq\left(1-\kappa_{1}\right) h_{1} w_{1}, \\
c_{2} \leq\left(1-\kappa_{2}\right) h_{2}\left(w_{1}+\phi h_{1}\right),
\end{gathered}
$$

where he takes $\kappa_{1} \geq 0$ and $\kappa_{2} \geq 0$ as given.

The first order conditions (again after substituting the multipliers, yielding in the range of admissible values again the global maximum) are

$$
\begin{aligned}
\frac{-b}{1-h_{1}}+\frac{\left(1-\kappa_{1}\right) w_{1}}{c_{1}}+\frac{\beta\left(1-\kappa_{2}\right) h_{2} \phi}{c_{2}} & =0, \\
\frac{-b}{1-h_{2}}+\frac{\left(1-\kappa_{2}\right)\left(w_{1}+\phi h_{1}\right)}{c_{2}} & =0, \\
\left(1-\kappa_{1}\right) h_{1} w_{1}-c_{1} & =0, \\
\left(1-\kappa_{2}\right) h_{2}\left(w_{1}+\phi h_{1}\right)-c_{2} & =0,
\end{aligned}
$$

For a meaningful comparison of the two different tax regimes, the revenue raised under both should be equal, so that

$$
\begin{array}{r}
\kappa_{1} h_{1} w 1=\tau_{1}, \\
\kappa_{2} h_{2}\left(w_{1}+\phi h_{1}\right)=\tau_{2} .
\end{array}
$$

The first order conditions together with the equations relating $\kappa_{1}$ and $\kappa_{2}$ to $\tau_{1}$ and $\tau_{2}$ 
give the agent's decision for given levels of tax revenue raised $\left(\tau_{1}\right.$ and $\left.\tau_{2}\right) .^{2}$ Also for this system of equations, numerical solutions can easily be obtained.

\section{Results}

I will illustrate the results with simple graphs that will give a good intuition of the working of the model. These results and their discussion are contained in Section 3.1. In Section 3.2, I discuss potential criticisms of the model and possible extensions to move it closer to a (large) quantitative behavioral optimal taxation model.

\subsection{Comparison of the Two Tax Regimes}

The main purpose is to compare the two tax regimes with respect to their social welfare, which is (discounted) experienced lifetime utility of the representative agent. The graphs below show how the difference in social welfare between a proportional tax and a lump-sum tax depends on each of the model parameters. The vertical axis shows the gain in social welfare when using a proportional labor (positive values thus correspond to higher welfare under a proportional tax than under a lump-sum tax and vice versa; the social welfare differences have been multiplied with 100 for convenience). The horizontal axis represents different parameter values.

All parameters except for the parameter under consideration are fixed at a standard calibration. This standard calibration is $\left(w_{1}, b, \beta, \phi, \tau_{1}, \tau_{2}, \delta\right)=(1,0.5,0.9,1,0.1,0.1,0.15)$. The qualitative features of the results are not very sensitive to the choice of this calibration (but, of course, the exact calculated quantities depend on it).

Figure 1a shows the effect of introducing aspirations into the model. The case of $\delta=0$ corresponds to the fully rational model where aspirations play no role. In that case, one obtains the classical result that a lump-sum tax leads to higher social welfare than a proportional labor tax. However, for increasing $\delta$, meaning that aspirations play

\footnotetext{
${ }^{2}$ If one prefers four equations in the four unknowns $c_{1}, h_{1}, c_{2}$ and $h_{2}$ corresponding to the system in Section 2.3 one can use Equations (6) and (7) substitute $\kappa_{1}$ and $\kappa_{2}$ in the first order conditions.
} 
a more important role, the advantage of a lump-sum tax vanishes and for sufficiently high $\delta$ a proportional labor tax leads to greater social welfare than a lump-sum tax.

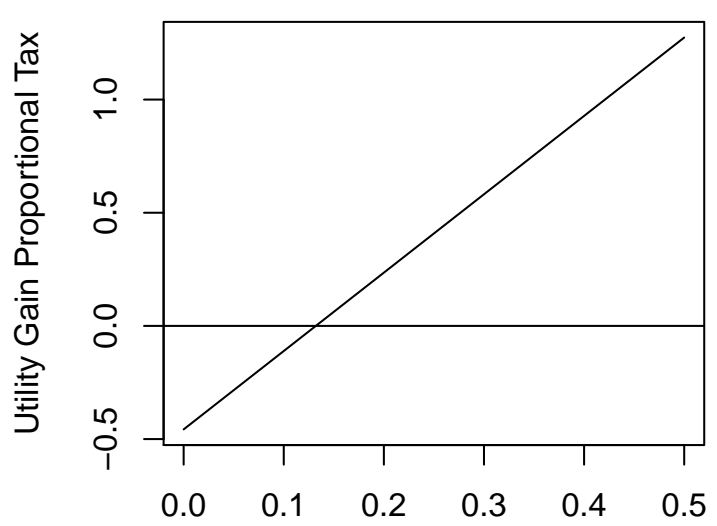

$\delta$

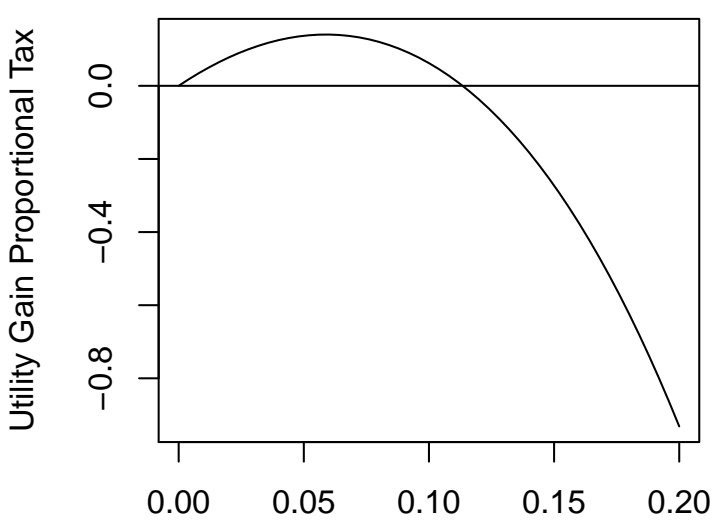

Figure 1: Differences in social welfare as functions of $\delta$ and $\tau:=\tau_{1}=\tau_{2}$

Notes: $\left(w_{1}, b, \beta, \phi, \tau_{1}, \tau_{2}\right)=(1,0.5,0.9,1,0.1,0.1)$ (left) and $\left(w_{1}, b, \beta, \phi, \delta\right)=(1,0.5,0.9,1,0.15)$ (right).

Figure $1 \mathrm{~b}$ shows the effects of changes in the collected tax revenue. For this graph we assume that $\tau_{1}$ and $\tau_{2}$ are kept equal and change simultaneously (indicated by $\tau:=\tau_{1}=\tau_{2}$; the proportional labor tax is of course always chosen such as to obtain the same tax revenue as indicated in Equations (6) and (7)). For $\tau=0$, that is, when no taxes are raised at all, the theoretical tax regime does naturally not matter. In this graph, we observe an inverse U-shape. When $\tau$ increases, we first observe an increase of the social welfare advantage of a proportional tax rate. The increasing part of this inverse $\mathrm{U}$ can be explained as follows. A proportional tax can be superior to a lump-sum tax, but for very low values of the tax, this hardly matters (we are close to $\tau=0$ where the social welfare must be equal between the two tax regimes). The higher the tax, the more the difference matters. However, this only holds up to a point. At some level of the tax, the welfare gain under a proportional tax starts to decrease as the effect of the disincentive to work becomes so large that labor supply becomes even lower than what would be optimal knowing of the aspirations. For a sufficiently high level of tax revenues raised, a lump-sum tax is then again superior to a proportional tax.

Figure 2a shows the effect of the discount factor $\beta$ in the model (which is equal 
in the decision utility and in the experienced utility). One can observe a monotonic increase of the social welfare difference in $\beta$. This is not surprising. All the disutility stemming from suboptimal choices due to the agent neglecting the changes in aspirations only enter the utility function of the second period. The less important the second period is for social welfare (i.e., the lower $\beta$ ), the less important is the effect of the aspirations. In relative terms, this means that the disutility in the first-period stemming from the distortion under a proportional tax becomes more important. Therefore, the higher is $\beta$, the higher is social welfare under a proportional tax.

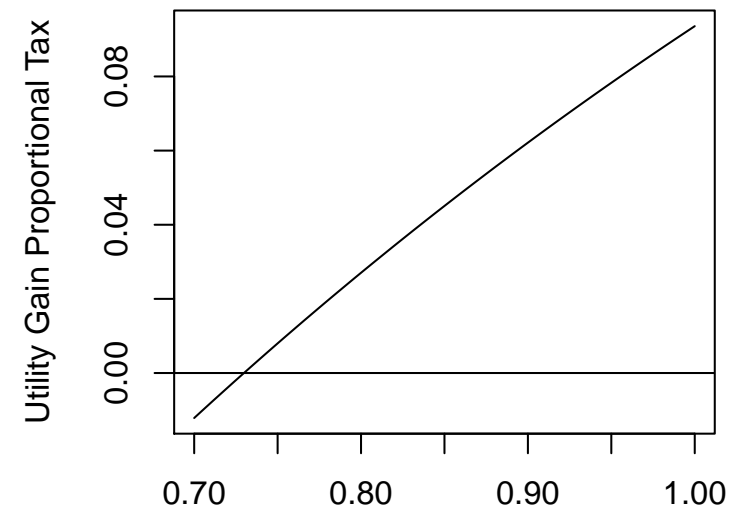

$\beta$

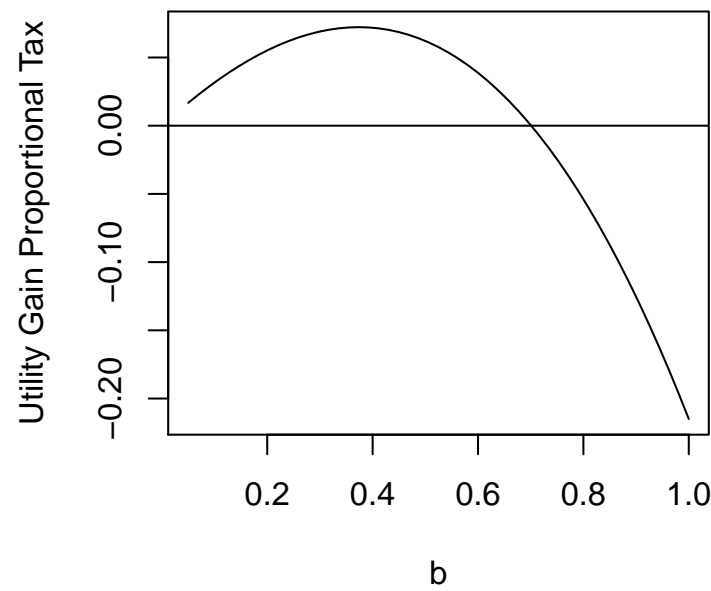

Figure 2: Differences in social welfare as functions of $\beta$ and $b$

Notes: $\left(w_{1}, b, \phi, \tau_{1}, \tau_{2}, \delta\right)=(1,0.5,1,0.1,0.1,0.15)$ (left) and $\left(w_{1}, \beta, \phi, \tau_{1}, \tau_{2}, \delta\right)=(1,0.9,1,0.1,0.1,0.15)$ (right).

Figure $2 \mathrm{~b}$ shows an inverse U-shape for the difference in social welfare as a function of $b$. For $b=0$ this difference is zero. This is very intuitive: if the agent does not care at all about leisure time the results of the two tax systems are equal, because in either case the agent works as much as possible. When $b$ increases from a zero level, a proportional tax increases in attractiveness. This is the case because then the effects of the aspirations kick in. That leisure matters for the agent means that he reduces work time more under a proportional tax. For low levels of $b$ this is welfare enhancing, because it offsets the excess labor that the agent would otherwise supply because he does not take into account that second-period experienced utility depends negatively on first-period consumption. However, when leisure is very important for the agent, 
also the distortionary effects from the proportional tax are very important (the agent reacts in a stronger way to the tax because leisure time is relatively more attractive than working). At some point, the incentive for the agent to reduce his labor supply is higher than the optimal level to offset the effects of the changing aspirations. Therefore, a lump-sum tax is relatively more attractive for high values of $b$.

The effects of the wage rate in the first period can be seen in Figure 3a. Again we can observe an inverse U-shape (albeit one that is less symmetrical than the ones before). For very low levels of the wage rate, lump-sum taxes are superior to proportional taxes. This is a region where working is not particularly attractive for the agent. This means that the overall level of consumption in the first period for the agent is low, so that differences in how much the agent consumes have a high impact on his utility. This makes the usual distortion from a proportional tax providing a disincentive to work particularly harmful. However, as $w_{1}$ increases a proportional tax becomes more interesting for a social welfare maximizing government as this effect becomes weaker (while the typical effect of the aspirations becomes more important meaning that the proportional tax reduces the excessive labor supply). For very high values of $w_{1}$, a lump-sum tax becomes relatively more attractive again.
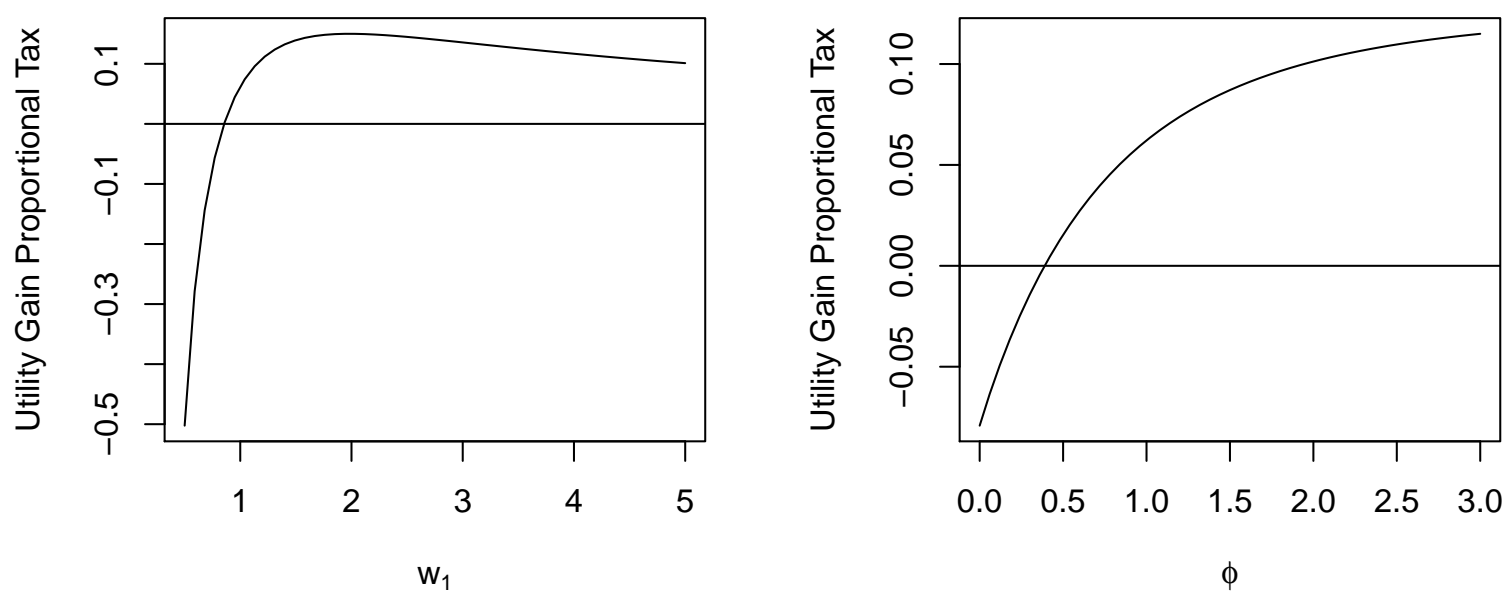

Figure 3: Differences in social welfare as functions of $w_{1}$ and $\phi$

Notes: $\left(b, \beta, \phi, \tau_{1}, \tau_{2}, \delta\right)=(0.5,0.9,1,0.1,0.1,0.15)$ (left) and $\left(w_{1}, b, \beta, \tau_{1}, \tau_{2}, \delta\right)=(1,0.5,0.9,0.1,0.1,0.15)$ (right).

Figure 3b shows the effect of the parameter determining how the period-two wage 
depends on work experience. The higher this parameter, the more attractive is a proportional tax. This is the case, because a higher value of $\phi$ makes the agent work more in the first period in order to benefit from a higher wage increase in the second period. However, this leads to a greater excess labor supply, which is mitigated by a proportional tax.

\subsection{Possible Extensions and Criticisms of the Model}

As already mentioned, this paper does not intend to provide a full-fledged quantitative model for policy analysis (such a model should include many behavioral mechanisms, many different kinds of taxes, etc.). Instead, the aim is to show one behavioral effect and to illustrate how even the most standard policy implication (lump-sum taxes are superior to proportional labor taxes when distributional concerns are absent) can change or even be turned upside down when agents are not fully rational. As for any model, one may claim that the model is unrealistic. Given that this is such a simple model, this is easy to do. In the following, I discuss some potential criticisms, which I mainly see as possible extensions to get to a larger quantitative behavioral public finance model.

One possible criticism is that savings or accumulation of capital are not possible in this model. This is true, but it is mainly to keep the model simple (which I was trying to do across the board without giving up its essence). I have little doubt that an extension of the model including saving or capital accumulation is possible, yielding qualitatively similar results (that is, the the general effects of aspirations persist, with the possibility that a proportional tax is superior to a lump-sum tax). Similarly, one may not be happy with a two-period framework. Also here, I have no doubt that the model could be extended to a multiple period model or to a model of an infinitely lived agent without changing the main result (keeping in mind that infinitely lived agent models are methodologically also quite questionable). Another critique could concern the exogeneity of some parameters, such as the wage rate in the first period. Once again, I do not doubt that it would be possible to come up with a competitive equilibrium model with endogenous wage rates where aspirations play a similar role. 
However, this would come at the expense of making a much more complicated model (that would probably not provide more insights).

In addition to the points discussed above, I believe that a few more features would be necessary to be introduced in a large-scale quantitative model, including the heterogeneity of agents, financial asset markets, and wage bargaining. Furthermore, all tax instruments that are available to a government should be in the model and analyzed jointly, as the availability of one tax instrument may in general influence the trade-offs between others. Such a quantitative model should then come together with sound behavioral assumptions about human behavior (the parameters of which would have to be estimated). This includes assuming present-biasedness and procrastination (e.g., O’Donoghue and Rabin, 2001; Burks et al., 2012; Sutter et al., 2013), expectation formation according to a reinforcement learning model (e.g., Heemeijer et al., 2009; Hommes, 2011; Bertasiute et al., 2018), and other-regarding behavior in the labor market (e.g., Fehr et al., 1998; Brandts et al., 2010; Casoria and Riedl, 2013). Some additional inclusions may have effects similar to those of aspirations (for example the introduction of different skill levels most likely makes a lump-sum tax unattractive as it does not account for the skill differences), others may have the opposite effect (for example present-biasedness, which should lead to agents supplying insufficient labor rather than excessive labor). ${ }^{3}$

A criticism of the model that I do not find acceptable is the criticism that rational choice should still be the main driver in economic models. Proponents of rational choice go a long way to defend it, coming up with arguments such as "maybe rational choice is not perfect, but we avoid getting lost in the wilderness of bounded rationality." Of course, this is nonsense, what is the value of a clearly defined benchmark if it is poor? Proponents of rational choice may also claim something along the lines of "well, maybe individuals are not rational, but on average their mistakes cancel out, so that

\footnotetext{
${ }^{3}$ As far as present-biasedness is concerned, it may well be that its effect and that of aspirations are not additive, meaning that present-biasedness could explain part of the behavior while aspirations explain another, without trivial implications on welfare or policy. A larger quantitative model encompassing both mechanisms could then possibly account for the facts that people on the one hand tend to postpone work to the future and do less than they had previously planned (present-biasedness) while they still ask themselves on their deathbed "was working so hard during all of my life really worth it?" (aspirations).
} 
the rational benchmark is still the best we have." This argument is similarly wrong - even when interested only in average mistakes across individuals, this claim would only be true if mistakes across individuals were uncorrelated, which they are usually not. Overall, such a broad literature documents that people are not rational, that their mistakes are often systematic and correlated (biases), and that they often use heuristics to make their decisions rather than attempting to optimize some sort of utility function that the critique of behavioral models on the basis that they are behavioral makes no (more) sense. ${ }^{4}$

\section{Concluding Remarks}

I have developed a simple two-period model introducing changing aspirations (the so called Easterlin Paradox; Easterlin, 2001) into an otherwise standard economic model. This model shows that the standard policy implication that lump-sum taxes are superior to proportional taxes can break down when this behavioral mechanism is present.

The intuition of the mechanism at work is that people may actually work too much under a lump-sum tax, because they think that their higher future income will make them happier than it actually will. The disincentives to work under the proportional labor tax decrease labor supply, which can actually be welfare increasing.

The model is not a large-scale quantitative model and does not incorporate most of what is going on in the real world. It comes with the caveat that I consider the discussed behavioral mechanism to play only a minor role in a real-world evaluation of the advantages and disadvantages of lump-sum and proportional labor taxes. This notwithstanding, I believe that the model provides a nice illustration of the effects of such a behavioral mechanism on the welfare consequences of the two discussed taxes.

\footnotetext{
${ }^{4}$ I also believe that basically anyone who has conducted economic experiments is very much aware of subjects' severe computational limitations and a variety of psychological drivers behind human behavior. In the experiments I conducted (Weber and Schram, 2017; Weber, 2017; Hommes et al., 2017; Weber et al., 2018; Kopányi-Peuker and Weber, 2018), the results always differ decisively from full rationality (the only experiment that also finds some support for rational behavior is the bond pricing experiment, Weber et al., 2018, where first-round prices are far from the equilibrium, but aggregate outcomes in the last round of the experiment are surprisingly close to the rational equilibrium).
} 


\section{References}

Bernheim, B. D. and Rangel, A. (2005). Behavioral public economics: Welfare and policy analysis with non-standard decision-makers. NBER Working Papers 11518, National Bureau of Economic Research, Inc.

Bertasiute, A., Massaro, D., and Weber, M. (2018). The behavioral economics of currency unions: Economic integration and monetary policy. Bank of Lithuania Working Paper No 49/2018.

Blumkin, T., Ruffle, B. J., and Ganun, Y. (2012). Are income and consumption taxes ever really equivalent? Evidence from a real-effort experiment with real goods. European Economic Review, 56(6):1200 - 1219.

Brandts, J., Gërxhani, K., Schram, A., and Ygosse-Battisti, J. (2010). Size doesn't matter! gift exchange in experimental labor markets. Journal of economic behavior \& organization, 76(3):544-548.

Burks, S., Carpenter, J., Götte, L., and Rustichini, A. (2012). Which measures of time preference best predict outcomes: Evidence from a large-scale field experiment. Journal of Economic Behavior \& Organization, 84(1):308-320.

Carpenter, J., Matthews, P. H., and Tabb, B. (2016). Progressive taxation in a tournament economy. Journal of Public Economics, 143:64-72.

Casoria, F. and Riedl, A. (2013). Experimental labor markets and policy considerations: Incomplete contracts and macroeconomic aspects. Journal of Economic Surveys, 27(3):398-420.

Chetty, R. (2015). Behavioral economics and public policy: A pragmatic perspective. American Economic Review, 105(5):1-33.

Chetty, R., Looney, A., and Kroft, K. (2009). Salience and taxation: Theory and evidence. American Economic Review, 99(4):1145-77. 
Easterlin, R. A. (2001). Income and happiness: Towards an unified theory. Economic Journal, 111(473):465-84.

Farhi, E. and Gabaix, X. (2015). Optimal taxation with behavioral agents. Technical report, National Bureau of Economic Research.

Fehr, E., Kirchler, E., Weichbold, A., and Gächter, S. (1998). When social norms overpower competition: Gift exchange in experimental labor markets. Journal of Labor economics, 16(2):324-351.

Fochmann, M., Kiesewetter, D., and Sadrieh, A. (2012). Investment behavior and the biased perception of limited loss deduction in income taxation. Journal of Economic Behavior and Organization, 81(1):230 - 242.

Gerritsen, A. (2016). Optimal taxation when people do not maximize well-being. Journal of Public Economics, 144:122-139.

Hagerty, M. R. and Veenhoven, R. (2003). Wealth and happiness revisited-growing national income does go with greater happiness. Social indicators research, 64(1):127.

Heemeijer, P., Hommes, C., Sonnemans, J., and Tuinstra, J. (2009). Price stability and volatility in markets with positive and negative expectations feedback: An experimental investigation. Journal of Economic dynamics and control, 33(5):1052-1072.

Hommes, C. (2011). The heterogeneous expectations hypothesis: Some evidence from the lab. Journal of Economic dynamics and control, 35(1):1-24.

Hommes, C. H., Massaro, D., and Weber, M. (2017). Monetary policy under behavioral expectations: Theory and experiment. Bank of Lithuania Working Paper No 42/2017.

Kahneman, D. (2003). Maps of bounded rationality: Psychology for behavioral economics. American Economic Review, 93:1449-1475.

Kahneman, D., Wakker, P. P., and Sarin, R. (1997). Back to bentham? Explorations of experienced utility. The Quarterly Journal of Economics, 112(2):375-406. 
Kerschbamer, R. and Kirchsteiger, G. (2000). Theoretically robust but empirically invalid? an experimental investigation into tax equivalence. Economic Theory, 16:719734.

Kopányi-Peuker, A. and Weber, M. (2018). Experience does not eliminate bubbles: Experimental evidence. Tinbergen Institute Discussion Paper 2018-092/II.

Kőszegi, B. and Rabin, M. (2008). Choices, situations, and happiness. Journal of Public Economics, 92(8-9):1821-1832.

McCaffery, E. J. and Baron, J. (2006). Thinking About Tax. Psychology, Public Policy, and Law, 12(1):106-135.

Mullainathan, S., Schwartzstein, J., and Congdon, W. J. (2011). A reduced-form approach to behavioral public finance.

O’Donoghue, T. and Rabin, M. (2001). Choice and procrastination. The Quarterly Journal of Economics, 116(1):121-160.

O’Donoghue, T. and Rabin, M. (2006). Optimal sin taxes. Journal of Public Economics, 90(10-11):1825-1849.

Riedl, A. (2010). Behavioral and experimental economics do inform public policy. FinanzArchiv: Public Finance Analysis, 66(1):65-95.

Sausgruber, R. and Tyran, J.-R. (2005). Testing the mill hypothesis of fiscal illusion. Public Choice, 122(1-2):39-68.

Sausgruber, R. and Tyran, J.-R. (2011). Are we taxing ourselves?: How deliberation and experience shape voting on taxes. Journal of Public Economics, 95(1-2):164-176.

Sutter, M., Kocher, M. G., Glätzle-Rüetzler, D., and Trautmann, S. T. (2013). Impatience and uncertainty: Experimental decisions predict adolescents' field behavior. American Economic Review, 103(1):510-31. 
Weber, M. (2017). Choosing the rules: Preferences over voting systems for assemblies of representatives. Journal of Economic Behavior and Organization. Forthcoming.

Weber, M., Duffy, J., and Schram, A. (2018). An experimental study of bond market pricing. Journal of Finance, 73(4):1857-1892.

Weber, M. and Schram, A. (2017). The non-equivalence of labour market taxes: A real-effort experiment. The Economic Journal, 127(604):2187-2215. 